
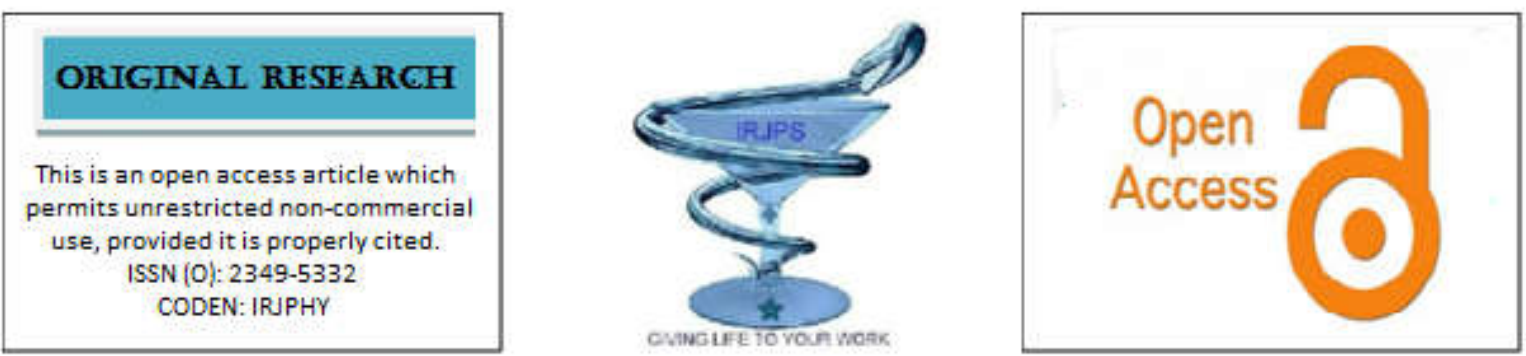

\title{
A SIMPLE VALIDATED RP-HPLC METHOD FOR THE ESTIMATION OF SITAGLIPTIN PHOSPHATE IN BULK AND PHARMACEUTICAL TABLET DOSAGE FORM
}

\author{
Jhansi Lakshmi Marreddy ${ }^{1 *}$, Sri Lakshmi Avuthu², Shaheem Sulthana Mohammad ${ }^{1}$
}

${ }^{1}$ Department of Pharmaceutical Analysis, ASN Pharmacy College, Tenali, Andhra Pradesh, India

${ }^{2}$ Department of Pharmacology, ASN Pharmacy College, Tenali, Andhra Pradesh, India

Submitted on: 29.09.19;

Revised on: 07.11.19;

Accepted on: 10.11.19

\begin{abstract}
:
A novel, simple and economic reverse phase high performance liquid chromatographic method was developed and validated as per the ICH guidelines for the quantitative estimation of Sitagliptin Phosphate in pharmaceutical tablet dosage form with greater precision and Accuracy. The mobile phase consisted of Methanol: acetonitrile: Orthophosphoric acid (40:55:5). The eluent was monitored at $265 \mathrm{~nm}$, at a flow rate of $1 \mathrm{~mL} / \mathrm{min}$ and retention time was observed at $10 \mathrm{~min}$. calibration curve as linear over the concentration range of $60-210 \mathrm{ng} / \mathrm{ml}$. RSD $\%$ of the determination of precision was $<2 \%$. Accuracy of method was determined through recovery studies which were found to be $99.82-101.87 \%$. The LOD and LOQ were found to be $0.05 \mathrm{mg} / \mathrm{mL}$ and $0.16 \mathrm{mg} / \mathrm{mL}$ respectively. Validation studies demonstrated that the proposed RP-HPLC method is simple, specific, rapid, reliable and reproducible. Hence the proposed method can be applied for the routine quality control analysis of Sitagliptin Phosphate in bulk and Pharmaceutical tablet dosage forms.
\end{abstract}

KEYWORDS: Sitagliptine Phosphate, LOD, LOQ, Recovery studies, ICH guidelines.

Corresponding author: J. L. Marreddy E-mail: jhansimarreddy@gmail.com \begin{tabular}{|c|}
\hline $\begin{array}{c}\text { Indian Research Journal of Pharmacy and Science; 22(2019)2000-2007; } \\
\text { Journal Home Page: https://www.irjps.in } \\
\text { DOI: } 10.21276 / \text { irjps.2019.6.3.10 }\end{array}$ \\
\hline
\end{tabular} 


\section{INTRODUCTION:}

Sitagliptin phosphate is described chemically as 7[(3R)-3-amino-1-oxo-4-(2,4,5trifluorophenyl) butyl]5,6,7,8-tetrahydro-3-(trifluoromethyl)-1,2,4triazolo[4,3-a]pyrazinephosphate monohydrate is shown as fig1. It has a molecular formula of $\mathrm{C}_{16} \mathrm{H}_{15} \mathrm{~F}_{6} \mathrm{~N}_{5} \mathrm{O} \cdot \mathrm{H}_{3} \mathrm{PO}_{4} \cdot \mathrm{H}_{2} \mathrm{O}$ and a molecular weight of 523.32. Sitagliptin Phosphate is an oral dipeptidyl peptidase-4 (DPP-4) inhibitor for the treatment of type II diabetes which improves glycaemic control by inhibiting DPP-4 inactivation of the incretin hormones glucagon like peptide -1(GLP-1) and glucose dependent insulinotropic polypeptide( GIP). This increase active incretin and insulin levels and decreases glucgon levels and post-glucose-load glucose excursion. Sitagliptin Phosphate is a white to off white, crystalline, non-hygroscopic powder. It is soluble in water and N, N-Dimethyl formamide; slightly soluble in methanol; very slightly soluble in ethanol, acetone and acetonitrile; and insoluble in isopropanol and isopropyl acetate. Several analytical methods based on UV Spectrophotometry, spectroflourimetry, RP-HPLC, HPTLC and LCMS/MS was reported for the determination of Sitagliptin Phosphate. Although literature survey reveals that various methods were reported in Sitagliptine Phosphate for single estimation and in combination with others drugs. Therefore the main objective of the proposed method was to develop simple, new accurate, precise, sensitive and robust RPHPLC method for the estimation of Sitagliptin Phosphate in bulk and tablet dosage form and validated as per ICH guidelines.

\section{MATERIALS AND METHODS:}

\section{Chemicals and reagents:}

Active pharmaceutical ingredient (API) working standard of Sitagliptin phosphate was received as gift samples from Mylan Laboratories Ltd., Hyderabad, India respectively. The Pharmaceutical dosage form used in this study was Januvia tablets manufactured by Merck Co. Ltd. which were purchased from local market. All chemicals and reagents used of HPLC grade.

\section{Instrumental and Chromatographic Conditions:}

Schimadzu LC20-AD HPLC system with Rheodyne universal injector 7725 and LC20-AD UV-Visible detector module equipped with Spinchrome software was used. The chromatographic studies were performed using Zodiac C18 column $(250 \times 4.6 \mathrm{~mm})$ with $5 \mu \mathrm{m}$ particle size and eluted with mobile phase consisting of methanol: Acetonitrile: $0.1 \%$ ortho phosphoric acid (40:55:05) and adjusted $\mathrm{pH}$ to 4.1 with triethyl amine at a flow rate of $1 \mathrm{~mL} / \mathrm{min}$. The run time was 10 minutes. The mobile phase was filtered through $0.45 \mu \mathrm{m}$ memberane filter and degassed in ultra Sonicator prior to use 10 minutes. Detection was made at $265 \mathrm{~nm}$. The injection volume was $20 \mu 1$ and all the experiments were performed at ambient temperature.

\section{Preparation of working standard solution:}

Accurately weighed $10 \mathrm{mg}$ of Sitagliptin phosphate working standard was taken in $10 \mathrm{ml}$ volumetric flask, dissolved and diluted to volume with mobile phase and mixed.

\section{Preparation of sample solution:}

Exactly 20 tablets were weighed and grinded to fine powder. A quantity of powder equivalent to $10 \mathrm{mg}$ of Sitagliptin phosphate was transferred in to a $10 \mathrm{ml}$ volumetric flask and dissolved in $7 \mathrm{ml}$ of diluent. The solution was sonicated for $15 \mathrm{~min}$ and shaken for $30 \mathrm{~min}$. then diluted to volume with diluent and mixed. 
Pipette out $1 \mathrm{ml}$ of the above stock solution into a $10 \mathrm{ml}$ volumetric flask and diluted up to the mark with diluent. Mix well and filter through $0.45 \mu$ membrane filter. The filtrate was injected for the further analysis.

\section{Method validation:}

\section{System suitability:}

From the chromatogram obtained for the standard preparation, the column efficiency was determined. The theoretical plates obtained should be not less than 2500 and the tailing factor should be not more than 2.0 and the relative standard deviation of replicate injection should be not more than $2.0 \%$.

\section{Accuracy:}

Accuracy of a method is defined as the closeness of a measured value to the true value. To carry out accuracy study of proposed method, the recovery studies were performed by spiking the previously analyzed sample of Sitagliptin phosphate with the known amounts of pure drug at different concentration levels. The spiked levels were 50\%, 100\% and 150\%. The $\%$ recovery was calculated three times at each level and the average $\%$ recovery was calculated.

\section{Linearity:}

Linearity is the ability of the method to respond proportionally to the changes in the concentration of the analyte in a sample. A series of solutions are prepared using Sitagliptin phosphate working standard at concentration levels from $60 \mathrm{ppm}$ to $210 \mathrm{ppm}$ of target concentration $(60,90,120,150,180$ and 210 ppm). The calibration curve was obtained by plotting the concentration against peak area of the each standard solution. The six concentration levels were subjected to regression analysis to calculate calibration equation and correlation coefficient.

\section{Limit of detection and Limit of quantitation:}

Limit of detection and Limit of quantitation represents the concentration of analyte that would yield signal to noise ratio of $3: 1$ and 10:1. The Limit of quantitation is approximately twice than that of Limit of detection.

\section{Precision:}

The precision of the method was determined by repeatability (intra-day) and intermediate precision (interday). Repeatability was determined by performing six repeated analysis of the same working solution of Sitagliptin phosphate, on the same day, under the same experimental conditions. The intermediate precision of the method was assessed by carrying out the analysis on different days and also by another analyst performing the analysis in the same laboratory (between-analysts).

\section{Robustness:}

For demonstrating the robustness of the developed method, experimental conditions were purposely altered and evaluated. Robustness of developed RPHPLC method was studied by effect on retention time of Sitagliptin phosphate by changing flow rate $( \pm 0.1$ $\mathrm{ml} / \mathrm{min})$, composition of organic phase $( \pm 1 \%)$ and $\mathrm{pH}$ of mobile phase $( \pm 0.1)$.

\section{RESULTS AND DISCUSSION:}

The method utilizing Methanol: Acetonitrile: orthophosphoric acid as mobile phase yielded broad peak, whereas with Methanol: Acetonitrile: orthophosphoric acid tailing was observed with methanol as diluent. Procedure utilizing Methanol: Acetonitrile: orthophosphoric acid as mobile phase with water as diluents also yielded tailing where as with Methanol: Acetonitrile: orthophosphoric acid mobile phase and acetonitrile as diluent sharp peak was obtained. During method development, a number 
of variations were tested like Methanol: concentration and flow rate to give a symmetric peak. With a mobile phase Methanol: Acetonitrile: orthophosphoric acid (40:55:5) at flow rate $1 \mathrm{ml} \mathrm{min-1}$ and wavelength is $265 \mathrm{~nm}$, symmetric peak was obtained.

\section{Linearity:}

The correlation coefficient value 0.9996 indicates that the method was linear over a concentration range of 60-210ppm for Sitagliptin phosphate.
Table 1: Data for linear graph

\begin{tabular}{|c|c|c|}
\hline S.NO & Concentration & Peak area \\
\hline 1. & 60 & 288728 \\
2. & 90 & 417581 \\
3. & 120 & 539793 \\
4. & 150 & 684954 \\
5. & 180 & 824260 \\
6. & 210 & 962211 \\
\hline
\end{tabular}

Table 2: Results for regression analysis

\begin{tabular}{|c|c|c|c|c|c|}
\hline S.NO & Drug name & $\begin{array}{c}\text { Linear dynamic range } \\
(\mathrm{ppm})\end{array}$ & $\begin{array}{c}\text { Correlation } \\
\text { coefficient }\end{array}$ & Slope & Intercept \\
\hline 1. & $\begin{array}{c}\text { Sitagliptin } \\
\text { phosphate }\end{array}$ & $60-210$ & 0.9996 & 4548.2 & 4780.5 \\
\hline
\end{tabular}

Table 3: Results for Accuracy

\begin{tabular}{|c|c|c|c|c|c|}
\hline Level & $\begin{array}{c}\text { Target in } \\
\text { ppm }\end{array}$ & $\begin{array}{l}\text { Amount of Sitagliptin } \\
\text { spiked(ppm) }\end{array}$ & $\begin{array}{c}\text { Total in } \\
\text { ppm }\end{array}$ & $\begin{array}{l}\text { Amount of Sitagliptin } \\
\text { recovered (ppm) }\end{array}$ & $\%$ Recovery \\
\hline \multirow[t]{3}{*}{$50 \%$} & 60 & 30 & 90 & 88.71 & 98.57 \\
\hline & 60 & 30 & 90 & 89.84 & 99.82 \\
\hline & 60 & 30 & 90 & 88.94 & 98.82 \\
\hline \multirow[t]{3}{*}{$100 \%$} & 60 & 60 & 120 & 119.57 & 99.64 \\
\hline & 60 & 60 & 120 & 120.62 & 100.51 \\
\hline & 60 & 60 & 120 & 121.02 & 100.85 \\
\hline \multirow[t]{3}{*}{$150 \%$} & 60 & 90 & 150 & 152.81 & 101.87 \\
\hline & 60 & 90 & 150 & 151.33 & 100.89 \\
\hline & 60 & 90 & 150 & 152.37 & 101.58 \\
\hline
\end{tabular}


Table 4: Results for System suitability

\begin{tabular}{|c|c|c|}
\hline \multirow{2}{*}{ S.No } & \multicolumn{2}{|c|}{ System suitability results } \\
\cline { 2 - 3 } & USP Plate count & USP Tailing \\
\hline 1 & 9564 & 1.28 \\
2 & 9942 & 1.34 \\
3 & 9375 & 0.56 \\
4 & 9515 & 0.66 \\
5 & 9383 & 0.78 \\
Mean & 9556 & 0.92 \\
\hline
\end{tabular}

Limit of detection and Limit of quantitation:

The Limit of detection (LOD) and Limit of quantitation (LOQ) represent the concentration of Sitagliptin phosphate stock solution in order to obtain signal-to- noise ratio of 3:1 for LOD and 10:1 for LOQ were determined.

Table 5: Results for LOD \& LOQ

\begin{tabular}{|c|c|c|}
\hline Sample & LOD & LOQ \\
\hline Sitagliptin phosphate & $0.05 \mu \mathrm{g} / \mathrm{ml}$ & $0.16 \mu \mathrm{g} / \mathrm{ml}$ \\
\hline
\end{tabular}

Table 6: Results for Robustness:

\begin{tabular}{|c|c|c|}
\hline Condition & Mean area & \% Difference \\
\hline Unaltered & 539793 & $\ldots \ldots \ldots$ \\
\hline Flow rate at $0.8 \mathrm{ml} / \mathrm{min}$ & 537519 & 0.42 \\
Flow rate at $1.2 \mathrm{ml} / \mathrm{min}$ & 538041 & 0.32 \\
\hline Mobile phase & & \\
\hline
\end{tabular}

\begin{tabular}{|c|c|c|}
\hline $\mathrm{MeOH}: \mathrm{ACN}: 0.1 \%$ & & \\
OP & 530367 & 1.75 \\
38:57:05 & 541617 & 034 \\
42:53:05 & & \\
\hline $\mathrm{pH}$ of mobile phase 4.0 & 538983 & 0.15 \\
$\mathrm{pH}$ of mobile phase 4.2 & 542948 & 0.58 \\
\hline
\end{tabular}

Table 7: Results for Intraday precision:

\begin{tabular}{|c|c|c|}
\hline Sample preparation & \multicolumn{2}{|c|}{ Observed values } \\
\cline { 2 - 3 } & Area & $\%$ Assay \\
\hline 1 & 536063 & $98.8 \%$ \\
2 & 535151 & $99.5 \%$ \\
3 & 530278 & $97.4 \%$ \\
4 & 532011 & $96.8 \%$ \\
5 & 539975 & $97.4 \%$ \\
6 & 526693 & $99.8 \%$ \\
Mean & 533362 & $98.2 \%$ \\
SD & 4691 & 0.01 \\
\%RSD & 0.88 & 1.27 \\
\hline
\end{tabular}

Table 8: Results for Interday precision:

\begin{tabular}{|c|c|c|}
\hline \multirow{2}{*}{ Day } & \multicolumn{2}{|c|}{ Observed values } \\
\cline { 2 - 3 } & Area & \% Assay \\
\hline 1 & 531868 & $97.1 \%$ \\
2 & 539113 & $98.4 \%$ \\
3 & 529707 & $97.8 \%$ \\
4 & 526726 & $99.7 \%$ \\
5 & 525325 & $98.9 \%$ \\
6 & 527193 & $97.4 \%$ \\
Mean & 529989 & $98.2 \%$ \\
SD & 5041 & 0.01 \\
\%RSD & 0.95 & 1.0 \\
\hline
\end{tabular}

Table 9: Quantitative estimation of tablet formulation

\begin{tabular}{|c|c|c|c|c|c|c|}
\hline Sl.No & Brand name & Standard area & Sample area & $\begin{array}{c}\text { Labelled claim } \\
(\mathrm{mg})\end{array}$ & $\begin{array}{c}\text { Amount found } \\
(\mathrm{mg})\end{array}$ & \%Purity \\
\hline 1 & Januvia & 539793 & 533644 & 100 & 98.50 & 98.50 \\
\hline
\end{tabular}




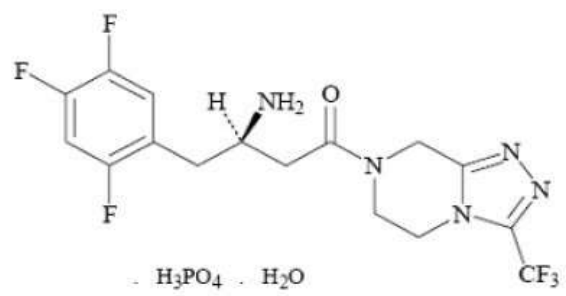

Fig1: Chemical structure of Sitagliptin Phosphate

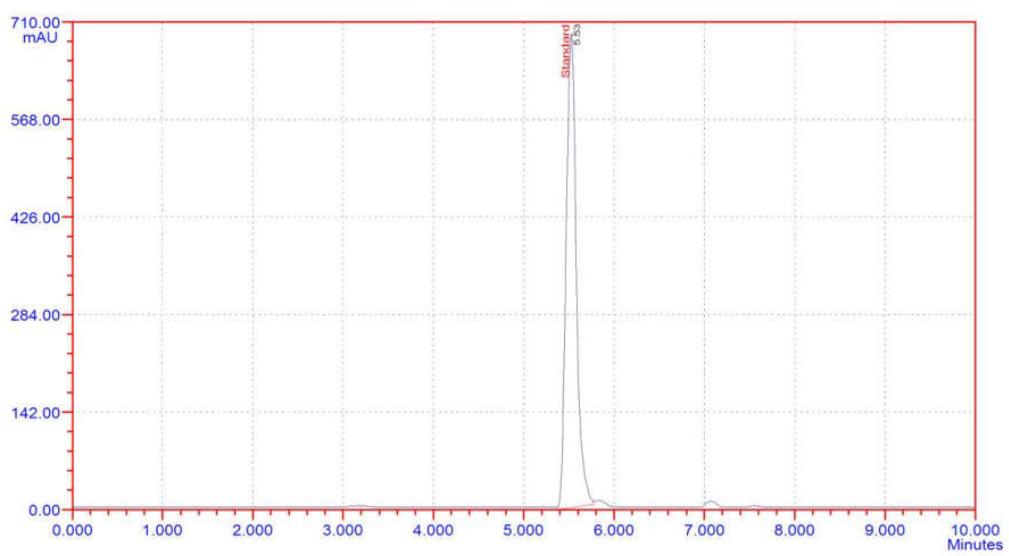

Fig 2: Standard Chromatogram of Sitagliptin Phosphate

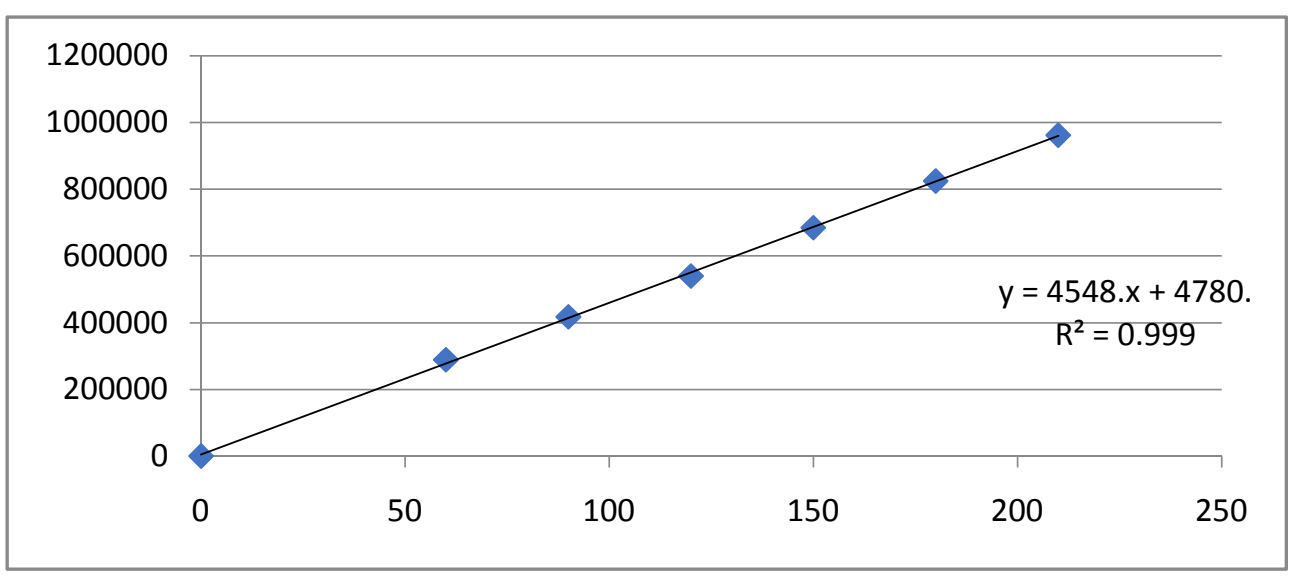

Fig 3: Calibration Curve of Sitagliptin Phosphate

\section{CONCLUSION:}

A validated RP-HPLC method has been developed for the quantitative determination of Sitagliptin Phosphate in bulk and pharmaceutical tablet dosage forms. The method was completely validated shows satisfactory results for all the method validation parameters tested and method was free from interference of the other active ingredients and additives used in the 
formulation. In fact, results of the study indicates that the developed method was found to be rapid, simple,

\section{REFERENCES:}

1. J. Anudeepa, R. Manavalan, R.Venkata, "Development of UV Spectrophotometric method for Sitagliptin in bulk and Pharmaceutical formulation", International Journal of Science, Engineering and Technology, 2015, 3(5): 13521354.

2. Amruta B. Loni, Minal R. Ghante, S. D. Sawant, "Simultaneous UV Spectrophotometric method for estimation of Sitagliptin phosphate and Metformin $\mathrm{HCl}$ in bulk and tablet dosage form", Der Pharma Chemica,2012,4(3): 854-859.

3. Karimulla S K, Vasanth P M, Ramesh T, Ramesh M, "Method development and validation of Sitagliptin and Metformin using Reverse phase HPLC method in bulk and tablet dosage form", Der Pharmacia Lettre,2013,5(5): 168-174.

4. Sachin L Patil, Jayant R Bhinge and Chetan M Bhagat, "Development and Validation of Stability Indicating RPHPLC Method for Simultaneous determination of Sitagliptin and Metformin in tablet dosage form", International Journal of Research in Pharmaceutical and Biomedical Sciences (IJRPBS), Apr-Jun 2013; Vol.4(2): 590596.

5. YaravedaLathareddy\& Naidu Srinivasa Rao, "Stability-indicating RP-HPLC method and its validation for analysis of metformin \&sitagliptin in bulk and pharmaceutical dosage form"World Journal Of Pharmacy And Pharmaceutical Sciences, Volume 2, Issue 5, 3691-3709.

6. Chellu S.N, Malleswararao, Mulaskutla V. Suryanarayan, KhaggaMukkauti, "Determination of Sitagliptin phosphate and Metformin hydrochloride in tablets by a validated UPLC specific, sensitive, precise, accurate and reliable that can be effectively applied for routine analysis.

method", ScientiaPharmaceutica, 2012; 80: 139152.

7. Gallwitz B. "Sitaglipitin: Profile of novel DPP-4 inhibitor for treatment of type- 2 diabetes". Drugs today 2007 ; 43(1): 13-25.

8. Barnard K. Cox ME. Green JB. "Clinical utility of fixed combinations of sitaglipitin- metformin in treatment of type- 2 diabetes". Diabetes. Metabolic Syndrome and Obesity. Targets and Therapy 2010; 3: 363-72.

9. BhimireddyVenkata Rami Reddy, Nanduri Raman, BadamSai Kumar, ChintalaRambabu. Chiral "separation of sitagliptin phosphate enantiomer by HPLC using amylose based chiral stationary phase", Journal of Pharmacy Research 2013;7(6): 546-550.

10. Ghazala K, Dinesh S, Agrawal YP, Neetu S, Avnish J, Gupta AK. "Simultaneous estimation of metformin and sitagliptin in tablet dosage form". Asian J Biochem Pham Res. 2011;2:223-9

11. Shyamala M, Mohideen S, Satyanarayana T, Narasimha Raju CH, Suresh Kumar P, Swetha K. "Validated RP-HPLC for simultaneous estimation of sitagliptin phosphate and metformin hydrochloride in tablet dosage form". Am J Pharm Tech Res. 2011;1:193-101.

12. Wang L, Asgharnejad M. ":Second derivative UV Spectrometric Determination of simvastatin in its tablet dosage form.”J Pharm Biomed Anal. 2000; 21:1, 243-8.

13. Patel TR, Patel TB, Suhagia BN. "Stability indicating RP-HPLC method for simultaneous estimation of simvastatin and sitagliptin in tablet 
dosage form”. Indo Am J Pharm Res. 2014;4:1993-9.

14. Parag Pathade et.al "stability indicating UV Spectrophotometric method has been developed for quantitative determination of Sitagliptin Phosphate in bulk and pharmaceutical formulations," Journal of Pharmacy Research, 2011; 4(3): 871-873.

15. Deepthi.v “A novel stability-indicating RP-HPLC method for quantitative analysis of Sitagliptin in the bulk drug and in its pharmaceutical dosage form," International journal of pharmacy and pharmaceutical sciences.2013; 5(1): 320-325.

16. Tarkase K.N et.al "UV spectrophotometric method has been developed for Estimation of Sitagliptin phosphate in tablet dosage form", Scholars Research Library 2013; 5 (3):315- 318. 